\title{
Impacts of Perceived Behavior Control and Emotional Labor on Gig Workers
}

\author{
Elizabeth B. Marquis \\ University of Michigan \\ School of Information \\ Ann Arbor, MI 48109, USA \\ ebmorris@umich.edu \\ Sangmi Kim \\ University of Michigan \\ School of Information \\ Ann Arbor, MI 48109, USA \\ sangmik@umich.edu

\section{Rasha Alahmad} \\ University of Michigan \\ School of Information \\ Ann Arbor, MI 48109, USA \\ rashama@umich.edu
}

\author{
Casey S. Pierce \\ University of Michigan \\ School of Information \\ Ann Arbor, MI 48109, USA \\ cbspierc@umich.edu \\ Lionel P. Robert Jr. \\ University of Michigan \\ School of Information \\ Ann Arbor, MI 48109, USA \\ Iprobert@umich.edu
}

Permission to make digital or hard copies of part or all of this work for personal or classroom use is granted without fee provided that copies are not made or distributed for profit or commercial advantage and that copies bear this notice and the full citation on the first page. Copyrights for third-party components of this work must be honored. For all other uses, contact the owner/author(s).

CSCW'18 Companion, November 3-7, 2018, Jersey City, NJ, USA.

Copyright is held by the author/owner(s).

ACM ISBN 978-1-4503-6018-0/18/10.

https://doi.org/10.1145/3272973.3274065

\begin{abstract}
Gig economy workers enjoy flexibility in choosing certain aspects of their work. Nonetheless, platform companies still need to control workers' behaviors to scale their business and ensure customers quality service. Mechanisms of control have been widely studied in traditional organizations; however, work in the gig economy differs from traditional organizations in that the role of a human supervisor is replaced with digital systems. Thus, there is reason to suspect that our traditional theories of control may not hold for new forms of work in the gig economy. To address these concerns, this study examines how gig economy workers, specifically Uber drivers, perceive behavior control and its effect on their job satisfaction. Our results suggest that emotional labor mediates the relationship between perceived behavior control and job satisfaction.
\end{abstract}

\section{Author Keywords}

Gig economy workers; control; emotional labor

\section{Introduction}

Job opportunities in the gig economy have become increasingly attractive for workers who seek flexibility to choose when, where and how much they want to work [1]. However, platform companies still enact control to coordinate millions of workers and offer their services at scale using their technology platforms [2]. 
Popular gig economy platforms:

- Uber

- Lyft

- Postmates

- Airbnb

- Task Rabbit
Hence, gig economy workers are not entirely free to conduct work at their own discretion, but must adjust to the ways in which they are controlled by platform companies if they want to continue gig work.

Control is defined as the mechanisms an organization uses to manage its workers to move towards its objectives [3]. Several prior studies have investigated the effects of control on worker outcomes, such as job satisfaction [4]. Because platform companies, such as ride-sharing services like Uber, currently rely on human workers to deliver their services to customers, there is importance for platform companies to understand gig economy workers' perspectives about control and how to best enact control to improve workers' outcomes.

While mechanisms of control have been widely studied in traditional organizations, research has yet to explore control mechanisms in the context of gig economy work [4]. A distinguishing feature of gig economy work from the work in traditional organizations is that the management of employees is delegated to a digital platform rather than performed by human supervisors or managers. Thus, our current understanding of control in the gig economy is underexplored.

\section{Background \& Hypotheses}

One of the ways platform companies enact control on gig economy workers is by seeking to control workers behaviors using rating systems. Taking Uber as an example, drivers' ratings are aggregated and used as a performance evaluation. In turn, a low rider rating can result in Uber reviewing a driver or even deactivating their account. Hence, the presence of the rating system acts as a tool of behavior control because it is meant to encourage positive behaviors among Uber drivers [5]

Furthermore, rating systems also influence Uber drivers to modify how they act in front of their customers (i.e., Uber riders). Emotional labor, or the regulation of emotions while at work, helps shape experiences surrounding organizational control [6]. Previous research has examined emotional regulation in customer service jobs, where workers such as food servers and flight attendants must directly engage with customers to deliver a good or service and regulate their emotions in order to satisfy the customer [7] Similarly, gig economy work also involves directly engaging with customers when delivering a good or service. As such, workers may perform different levels of emotional labor depending on what work is required to maintain positive customer interactions.

Specifically, emotional labor involves two strategies in how workers regulate their emotions: surface acting and deep acting. Surface acting refers to when a worker feels one way inwardly, but outwardly displays a different expression to satisfy the customer. Deep acting involves workers actually changing how they fee inwardly to match the customers' expectations in order to express genuine [8]. In this way, emotional labor places demands on the worker to act in positive ways in order to gain the customer's favor. Similarly, gig work also involves directly engaging with customers, such as when Uber drivers interact with their riders, in order to achieve positive ratings.

However, gig economy work is heavily technologicallymediated, which in turn influences the lack of defined rules and norms regarding in-person emotional regulation [9]. To this point, Uber drivers have reported a perceived need to meet their customers' social and emotional needs due to the expectation that each customer will evaluate the driver through the Uber rating system $[9,10]$. Moreover, recent work has shown rating systems are significant in the gig economy as they greatly influence how service providers are selected and allocated work [11]. Therefore, there is reason to suspect that emotional labor - including deep and surface level acting - may mediate the relationship between perceived behavior control and job satisfaction among gig economy workers. Taken together, we propose two hypotheses: 
- Control was measured using an adapted four-item behavior control scale [12]. Eg. "Uber monitors the extent to which I follow established procedures".

- Deep and surface acting were both adapted 3-item scales [7]. Deep acting included items such as "I make an effort to actually fee the emotions that I need to display when interacting with my Uber riders". Surface acting included items such as "I resist expressing my true feelings when interacting with my Uber riders"

- Job satisfaction was measured by a 4 item scale [13]. Eg. "All in all, I am very satisfied with my job as an Uber driver"

- Control variables: age, gender, race, marital status, tota household income, income from Uber per week.
H1: Uber drivers' perceptions of more behavior control will be associated with more reported emotional labor (deep acting, surface acting).

H2: Emotional labor will mediate the relationship between Uber drivers' perceptions of behavior control and job satisfaction.

\section{Method}

To test our hypotheses, we conducted we conducted survey of Uber drivers. Respondents were recruited through a survey panel run by Qualtrics. Three responses were excluded from the analyses due to missing data $(n=108)$. Respondents were 32.77 years old on average, $52.25 \%$ female, $72.32 \%$ white, and made $\$ 346.03$ per week driving for Uber on average.

All analyses were conducted in SPSS 24. Continuous variables were standardized. Hierarchical linear regression was used to test $\mathrm{H} 1$. Two models were run: one with just perceived behavior control and one with control variables included. $\mathrm{H} 2$ two was tested using a Sobel test to assess mediation.

\section{Results}

H1: Perceived behavior control is positively related to deep acting after controlling for demographics $(p<.001)$. Higher levels of perceived behavior control are associated with higher levels of deep acting. Uber behavior control is not significantly related to surface acting $(p=.07)$. H1 was partially supported.

H2: Surface acting was not tested for mediation due to not being significantly related to Uber behavior control. Deep acting significantly mediates the relationship between Uber behavior control and job satisfaction. $\mathrm{H} 2$ was supported.

In sum, perceived behavior control positively predicts deep acting and job satisfaction. Deep acting mediates the relationship between perceived behavior control and job satisfaction.

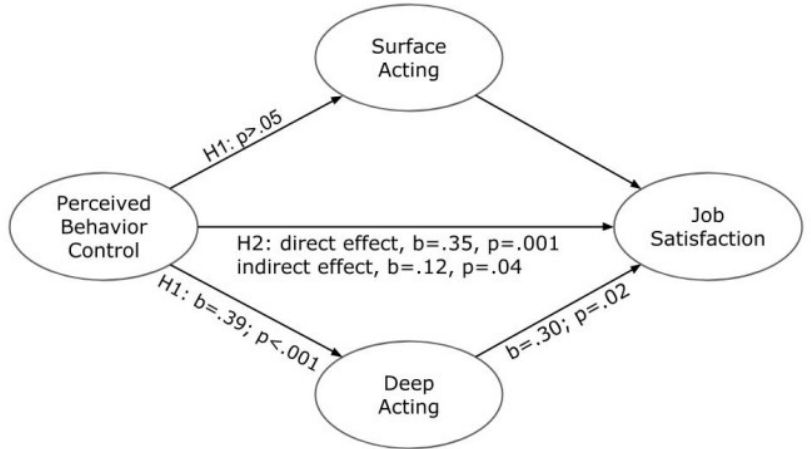

Figure 1. Hypotheses 1 and 2

\section{Discussion}

This work builds upon previous work about platform companies use of control mechanisms upon gig economy workers [14]. Moreover, as recent work examining the precarity of gig economy work [15], it is important to examine how platform companies enact control through technology. Because platform companies enact control through digital artifacts, such as apps, it is also important to consider design implications of gig work. Our preliminary results suggest that perceived behavior control, as it is enacted through customer ratings reported through the Uber app, influences job satisfaction. Moreover, these results also that emotional labor can be managed by platform companies to control the behavior of their employees.

Future work should examine behavior control across platform companies. First, considering other platforms is an opportunity examine if there are differences across different types of work in the gig economy that require expertise or skills for the task at hand (e.g. TaskRabbit). Second, because control in the gig economy is technologically mediated through an array of applications, it's important to compare across types of platform companies to examine how the form and 
function of these applications (i.e., digital materiality) affects how workers perceive behavioral control.

\section{References}

[1] Aaron Smith. 2016. Gig work, online selling and home sharing. Pew Research Center, 17.

[2] Mark de Reuver, Carsten Sorensen, and Rahul C. Basole. 2018. The digital platform: a research agenda. Journal of Information Technology, 33(2), 124-135.

[3] William G. Ouchi. 1979. A conceptual framework for the design of organizational control mechanisms. In Readings in accounting for management control ( $\mathrm{pp}$.

63-82). Springer, Boston, MA.

[4] Laura B. Cardinal, Markus Kreutzer, and C. Chet Miller. 2017. An aspirational view of organizational control research: Re-invigorating empirical work to better meet the challenges of 21st century

organizations. Academy of Management Annals, 11(2), 559-592.

[5] Min Kyung Lee, Daniel Kusbit, Evan Metsky, and Laura Dabbish. 2015, April. Working with machines: The impact of algorithmic and data-driven management on human workers. In Proceedings of the 33rd Annual ACM Conference on Human Factors in Computing Systems (pp. 1603-1612). ACM.

[6] Stephen Fineman and Andrew Sturdy. 1999. The emotions of control: A qualitative exploration of environmental regulation. Human Relations, 52(5), 631-663.

[7] Alicia A. Grandey. 2000. Emotional regulation in the workplace: A new way to conceptualize emotional labor. Journal of occupational health psychology, 5(1), 95.

[8] Celeste M. Brotheridge and Raymond T. Lee. 2003. Development and validation of the emotional labour scale. Journal of Occupational and Organizational Psychology, 76(3), 365-379.

[9] Noopur Raval and Paul Dourish. 2016, February. Standing out from the crowd: Emotional labor, body labor, and temporal labor in ridesharing. In Proceedings of the 19th ACM Conference on Computer-Supported Cooperative Work \& Social Computing (pp. 97-107). ACM.

[10] Mareike Glöss, Moira McGregor, and Barry Brown. 2016, May. Designing for labour: Uber and the ondemand mobile workforce. In Proceedings of the 2016 CHI conference on human factors in computing systems (pp. 1632-1643). ACM.

[11] Teng Ye, Casey Pierce, Rasha Alahmad, and Lionel P. Robert. 2017. Race and Rating on Sharing Economy Platforms: The Effect of Race Similarity and Reputation on Trust and Booking Intention in Airbnb, Proceedings of the 38th International Conference on Information Systems (ICIS 2017).

[12] Bernard J. Jaworski and Deborah J. MacInnis. 1989. Marketing jobs and management controls: toward a framework. Journal of Marketing Research, 406-419.

[13] Gretchen M. Spreitzer. 1995. Psychological empowerment in the workplace: Dimensions, measurement, and validation. Academy of management Journal, 38(5), 1442-1465.

[14] Amrit Tiwana. 2013. Platform Ecosystems: Aligning Architecture, Governance, and Strategy (Morgan Kaufmann, San Francisco)

[15] Brenton J. Malin and Curry Chandler. 2016. Free to work anxiously: Splintering precarity among drivers for Uber and Lyft. Communication, Culture \& Critique, $10(2), 382-400$ 